\title{
Optimizing conditions for methylmercury extraction from fish samples for GC analysis using response surface methodology.
}

\begin{abstract}
Response surface methodology (RSM) was used to determine the optimum experimental conditions to extract methylmercury from fish samples for GC analysis. The influence of four variables - acid concentration (3-12 M), cysteine concentration $(0.5-2 \% \mathrm{w} / \mathrm{v})$, solvent volume (3-9 $\mathrm{ml})$ and extraction time (10-30 $\mathrm{min})$ - on recovery of methylmercury was evaluated. The detection limit for methylmercury analysis using a microelectron capture detector was $7 \mathrm{ng}$ g1 in fish samples. The mean recovery under optimum conditions was $94 \%$. Experimental data were adequately fitted into a second-order polynomial model with multiple regression coefficients $(\mathrm{r} 2)$ of 0.977 . The four variables had a significant effect $(\mathrm{p}<0.05)$ on the recovery of methylmercury from a reference material (BCR-463). Optimum conditions for methylmercury extraction were found using an acid concentration of $12.2 \mathrm{M}$, cysteine concentration of $2.4 \%$, solvent volume of $1.5 \mathrm{ml}$ and extraction time of $35 \mathrm{~min}$. The validation of the developed method to analyze methylmercury in fish samples exhibited good agreement with mercury content in the samples.
\end{abstract}

Keyword: Fish; Methylmercury; Extraction; RSM; GCmECD. 